\title{
Filling the gap between knowing and doing
}

\section{Research into delivery systems is needed to translate knowledge into improved health.}

Sir - Your Editorial "In praise of Gates" (Nature 425, 435; 2003) urged the Bill \& Melinda Gates Foundation to fund more upstream areas of basic research. I believe you are off the mark on this one.

The philanthropy of Bill Gates and its initial focus on neglected, high-burden diseases provide an important boost for the developing world. But I believe that the biggest gulf is between what we know and what we do in practice - the 'know-do' gap.

Although I would in no way deny the value of biomedical and upstream basic research, I believe we have placed too much emphasis on that and not enough on the translation of knowledge into actions to improve people's health. Although programmes such as Roll Back Malaria and the Global Fund for TB, Malaria and AIDS are aimed at tackling these issues on the ground, they do not support research in this area. They need to consider the knowledge gaps that have to be addressed so that their programmes have the desired impact.

Research into public-health systems and services and the contribution of the social and behavioural sciences (economics, anthropology, sociology and so on) are neglected fields. This is increasingly being recognized and addressed for specific diseases, but a more systematic approach is needed, which may benefit the entire health sector. Such research is critical in linking basic research to healthcare delivery, and in obtaining the participation and support of the people at whom new interventions are targeted.

For the Bill Gates billions to make a difference, a robust and efficient health system is needed in the countries where he hopes to have an impact. Without this, the multitude of new vaccines and drugs developed will have a negligible effect in reducing disease burdens.

To focus global attention on this neglected area, the World Health Organization will release a major report in 2004 entitled Knowledge for Better Health. The report's release will be linked with a global Summit on Health Research, to be held in Mexico in November 2004. We hope to convene a high-level gathering of leaders from the public, private and non-governmental sectors, the scientific community and the funders of health research to develop an action plan to address the key challenges of translating knowledge into health policy.

You referred to PPPs - public-private partnerships - as a successful means of bringing malaria drugs to market. No arguments there. But PPP could also stand for "publications, patents and professorships" — the mindset of many scientists in basic research.

It is my hope that the philanthropy of Bill Gates, through appropriate funding of research, will help to nurture another PPP mindset of "policy, practice and people". He should put more of his money into research that will ensure that his laudable investments to date will have a real impact in improving the health and well-being of poor populations in the developing world.

Tikki Pang

Research Policy and Cooperation, World Health Organization,

Avenue Appia, 1211 Geneva 27, Switzerland
Open access: the $\mathrm{JCI}$ has already shown it works

Sir - There has been much media attention surrounding the launch of the new open-access journal, PLoS Biology (see, for example, Nature 425, 554-555; 2003), which many scientists like myself hope will prove to be a success. However, some of the claims of originality for this venture are not warranted. The proposed model, in which authors pay the costs of free electronic access, has already been tested successfully by an existing highprofile periodical, the Journal of Clinical Investigation (JCI). Since the JCI went online (www.jci.org) in 1996, its content has remained completely free to everyone, with no barrier of any kind (J. B. Hawley J. Clin. Invest. 112, 968-969; 2003). This fits with the philosophy of its parent organization, the American Society for Clinical Investigation (ASCI).

Although the publishing and financial models of the JCI are not exactly the same as those of PLoS Biology, the only major difference appears to be that the ASCI holds copyright to articles. However, this is meant primarily to ensure the long-term integrity of the published work, and authors are not prevented from using the electronic version in any way that would advance the cause of science.

Overall, the positive experience of the JCI with author-paid electronic free access augurs well for the future of PLoS Biology, and for other journals that may choose to take this path.

Of course, the same model may not apply easily to journals such as Nature, which also have to cover the costs of extensive front matter and general science policy and news reporting, thus serving a somewhat different role in scientific publishing.

Ajit Varki

Department of Medicine, University of California, San Diego, 9500 Gilman Drive, La Jolla, California 92093-0687, USA

Dr Varki has previously served as editorin-chief of the JCI and president of the ASCI - Editor, Correspondence

\section{Aircraft give a new view of jellyfish behaviour}

Sir - In her recent News Feature "Close encounters of the jelly kind" (Nature 426, 12-15; 2003) Carina Dennis describes the use of submersibles to catalogue jellyfish in the ocean. However, it is not just in the inaccessible deep ocean that technology is helping to improve our knowledge of jellyfish: the same applies to coastal areas. For example, scientists have struggled for more than half a century to record the distribution and abundance of giant Rhizostoma jellyfish in British and Irish waters. Today, low-flying aircraft are being used to survey wide areas.

This method revealed huge numbers of Rhizostoma - roughly one per square metre - in Carmarthen and Tremadoc bays in Wales from April to November this year. What drives these jellyfish to aggregate in these two large bays is unknown. However, both of these Welsh bays are known hotspots for sightings of jelly-feeding leatherback turtles, suggesting that some top predators are able to take advantage of this annual jelly-feast.

Graeme C. Hays ${ }^{\star}$, Jon. D. R. Houghton*, Tom Doyle $\dagger$, John Davenport $\dagger$ *School of Biological Sciences, University of Wales Swansea,

Singleton Park, Swansea SA2 8PP, UK

$\dagger$ Department of Zoology, Ecology and Plant Science, University College Cork, Lee Maltings,

Prospect Row, Cork, Ireland

\section{correspondence}

Contributions to Correspondence may be submitted to corres@nature.com. They should be no longer than 500 words, and ideally shorter. Published contributions are edited. 